\title{
POTENTIAL APPLICATION OF NOTOCHORDAL CELLS FOR INTERVERTEBRAL DISC REGENERATION: AN IN VITRO ASSESSMENT
}

\author{
E. Potier ${ }^{1,2}$, S. de $\operatorname{Vries}^{1}$, M. van Doeselaar ${ }^{1}$ and K. Ito ${ }^{1,3, *}$ \\ ${ }^{1}$ Orthopaedic Biomechanics, Department of Biomedical Engineering, Eindhoven University of Technology, \\ Eindhoven, the Netherlands \\ ${ }^{2}$ Univ Paris Diderot, Sorbonne Paris Cité, Laboratoire de Bioingénierie et Biomécanique Ostéo-articulaire, \\ UMR CNRS 7052, Paris, France \\ ${ }^{3}$ Department of Orthopaedics, University Medical Center Utrecht, Utrecht, the Netherlands
}

\begin{abstract}
Recent studies suggest that notochordal cells (NCs) might be involved in intervertebral disc homeostasis, a role exploitable to counteract matrix degradation as observed during degeneration. This study aimed to evaluate the potential of NCs to promote matrix production by nucleus pulposus cells (NPCs) and to compare it to the currently proposed addition of bone marrow stromal cells (BMSCs). Using alginate beads, bovine NPCs were exposed for $28 \mathrm{~d}$ to porcine $\mathrm{NC}$ conditioned medium (NCCM); direct co-culture with porcine NCs or bovine BMSCs; or the combination of BMSCs and NCCM. Effects on cell proliferation, disc matrix production (proteoglycans, collagens) and disc matrix protein expression (aggrecan, collagen 1 and 2, SOX9) were determined and compared to TGF $\beta$ stimulation. NCCM strongly promoted NPC proliferation (x 2.2) and matrix production (x 3.9) to levels similar to that with TGF $\beta$, whereas the direct addition of NCs had no effect. Co-culture of NPCs and BMSCs led to proteoglycan synthesis similar to NPCs alone, which was slightly improved by NCCM (x 1.5). Histological analysis confirmed biochemical data. Gene expression of analysed proteins remained stable for all groups and unaffected by medium conditions. NCs could substantially stimulate NPCs through factors secreted into conditioned medium and in levels similar to the addition of BMSCs. This study showed that molecular agents secreted by NCs constitute a promising alternative to the proposed "standard" injection of BMSCs for disc repair: their effects are similar, do not require the injection of a large number of cells and can be further amplified when the factors are identified.
\end{abstract}

Keywords: Intervertebral disc, notochordal cells, bone marrow stromal cells, cell therapy, nucleus pulposus cells, cell communication.

\author{
*Address for correspondence: \\ Prof. Keita Ito \\ Orthopaedic Biomechanics \\ Department of Biomedical Engineering \\ Eindhoven University of Technology \\ P.O. Box 513, GEM-Z 4.115 \\ 5600 MB Eindhoven \\ The Netherlands
}

Telephone Number: +31 402473851

FAX Number: +31 402473744

E-mail: k.ito@tue.nl
Introduction

Intervertebral discs are the structures lying between the vertebral bodies and transmitting loads exerted on the spine while allowing stable mobility in multiple directions. This stress redistribution function is ensured by a water rich, compressible core, the nucleus pulposus (NP), surrounded by a firm, fibrous outer layer, the annulus fibrosus. During degeneration, the NP transforms from a cartilage-like to a fibrous tissue (Antoniou et al., 1996), with a decrease in NP water content, resulting in reduced height and load-bearing capacities of the disc. Compressive forces are not evenly distributed anymore and abnormal stress concentrations are exerted on adjacent structures (annulus fibrosus and end plates). This stress redistribution may then trigger different tissue responses, such as inflammation, osteoarthritic changes, osteophyte formation, etc., which are all able to internally stimulate pain receptors. The abnormal stress distribution can also lead to the rupture of the annulus, allowing the NP to herniate outside of its confinement, which may ultimately compress and irritate the spinal cord and nerves. Furthermore, through such ruptures, neo-innervation of the disc may occur. Through all of these mechanisms, disc degeneration constitutes one of the main causes of low back pain (Zhang et al., 2009), a condition with substantial socio-economic impact (Katz, 2006). It appears, then, crucial to restore the original NP function to resolve this painful condition. Actual treatments, however, aim to replace (disc prosthesis) or immobilise (spinal fusion) the disc, which can aggravate the situation in other discs by altering further the biomechanics of the spine. In contrast, regenerative therapies aim to restore the NP to its original cartilage-like state, thus restoring healthy biomechanics of the entire spine.

As disc degeneration is characterised by a diminished number and catabolic behaviour of NP cells (NPCs) (Roberts et al., 2006), regenerative therapies rely on stimulating proliferation and matrix production of NPCs or replenishing the existing cell pool with regenerative cells able to make healthy NP tissue. Based on the observation that degeneration begins to occur soon after the disappearance (Smolders et al., 2013), or change of phenotype, of another cell type in the NP, the notochordal cells (NCs), it is now hypothesised that disc homeostasis may be thrown out of balance by this event. In vitro experiments with human (Abbott et al., 2012) and bovine (Aguiar et al., 1999; Gantenbein-Ritter and Chan, 2012) NPCs encapsulated in 3D hydrogels, indeed, suggest that NCs could act as stimulators, controlling NPC synthetic 
activity of proteoglycans (a main component of disc matrix) through secreted factors. Other studies have also shown that NCs could constitute a source of NPC-like cells, as they can produce proteoglycans and express type II collagen and aggrecan (Kim et al., 2009; Cappello et al., 2006) (main constituents of NP matrix) at levels similar to NPCs.

While these results demonstrate a promising and highly interesting potential of NCs for disc repair, bone marrow stromal cells (BMSCs) have also been proposed and studied since many years as a cell source for NPC replacement (Gilbert et al., 2013). In fact, their ability to stop disc degeneration has already been proven in different animal models (Henriksson et al., 2009; Hiyama et al., 2008; Sakai et al., 2006). Recent pilot clinical trials have even showed that they could successfully reduce pain and disability in low back pain cases (Orozco et al., 2011; Yoshikawa et al., 2010). BMSCs, however, could not restore disc height to healthy control level (Orozco et al., 2011; Yoshikawa et al., 2010), a shortcoming also observed in the animal studies (Henriksson et al., 2009; Hiyama et al., 2008; Sakai et al., 2006). Thus, BMSCs may require an additional push in order to produce enough matrix to restore the NP to a healthy state. Interestingly, NCs have also been shown to promote disc matrix protein expression and proteoglycan synthesis by BMSCs (Korecki et al., 2010; Purmessur et al., 2011).

All these studies have stirred the interest of the disc community for NCs, but it is still unclear what approach between molecular stimulation of resident cells and/or addition of regenerative cells could be the most effective to promote disc healing due to the various experimental conditions used in the studies. The aim of the present study was therefore to evaluate the different potential applications of NCs to promote disc matrix and, for the first time, to compare them directly to the "standard", and partly successful, addition of BMSCs._NC-rich porcine NP tissue was used to produce NC conditioned medium (NCCM), containing factors released by NCs, or isolate clustered NCs. Using an in vitro system where bovine NPCs were seeded into alginate beads, we evaluated, after $28 \mathrm{~d}$ of culture, the effects on matrix formation and cell behaviour of: (i) the exposure to factors secreted by NCs (NPCs under NCCM); (ii) the inclusion of potential NPC-like cell source (NPCs + NCs); and (iii) the addition of regenerative cells (NPCs + BMSCs) with or without NCCM. The ability of NCs to prime BMSCs via molecular factors was also evaluated (BMSCs under NCCM). Finally, for all cell combinations, NCCM effects were compared to standard TGF $\beta$ stimulation.

\section{Materials and Methods}

\section{Cell sources}

All slaughterhouse materials were obtained in accordance with local regulations. Bovine NPCs were obtained from caudal intervertebral discs harvested from 16 young adult cows (22-26 months old, without NCs in NP; cells from 4 donors pooled per independent sample). Discs were dissected and the NPs harvested under sterile conditions.
NPs were then digested following a sequential pronase (Calbiochem, Darmstadt, Germany)/ collagenase type 2 (Worthington, Lakewood, NJ, USA) digestion (Aguiar et al., 1999). Using a cell strainer, cells smaller than $100 \mu \mathrm{m}$ were kept after digestion and rinsed in plain medium before use. Cells from different donors were pooled in order to obtain a number large enough for each repeat without having to expand the NPCs, which may induce their dedifferentiation. Bovine BMSCs were isolated from bone marrow aspirates of 8 juvenile cows (4-12 months old, accessible in slaughterhouse for iliac crest bone marrow aspiration; cells from 2 donors pooled per independent sample) by adhesion (Kon et al., 2000; Potier et al., 2007) and expanded in plain medium [high glucose Dulbecco's modified Eagle's medium (hgDMEM; Gibco, Carlsbad, CA, USA) + $1 \%$ penicillin/streptomycin $(\mathrm{P} / \mathrm{S}$; Lonza, Basel, Switzerland)], supplemented with $10 \%$ foetal bovine serum (FBS Gold; PAA, Piscataway, NJ, USA) before freezing. A new batch of BMSCs was thawed and cultured up to P3 for each experiment. Cells from each donor were cultured separately then pooled for the experiment, using 2 donors (1:1) per independent sample. BMSCs were pooled in order to minimise the impact of donor variability on measured parameters and obtain enough cells at low passages. Porcine NCs were isolated from lumbar and thoracic intervertebral discs harvested from 4 young pigs ( $<10$ weeks old). NPs were harvested as previously described and digested at $37{ }^{\circ} \mathrm{C}$ as follows: $60 \mathrm{~min}$ in $0.1 \%$ Pronase in plain medium; $16 \mathrm{~h}$ in $0.01 \%$ collagenase $\mathrm{P}$ (Roche, Basel, Switzerland) in plain medium. Using a cell strainer, cells bigger than $40 \mu \mathrm{m}$ were kept after digestion. Qualitative assessment by inverted microscope of the cell suspensions obtained after tissue digestion but before cell filtration showed that large cells with big vacuoles (NCs) composed the large majority of cells, small cells without vacuoles (NPCs) only representing less than $10 \%$ of the total cell number (see Fig. 2 for representative NPC and NC morphology). These findings were in line with the reported cell composition of young $(<8$ months old) pig NPs (Chen et al., 2006; Purmessur et al., 2011).

\section{NC conditioned medium preparation}

NCCM was produced as described before (Abbott et al., 2012; Purmessur et al., 2011) from lumbar and thoracic intervertebral discs harvested from 4 young pigs $(<10$ weeks). NP fragments were obtained following the dissecting protocol previously explained and cultured directly (without tissue digestion) in plain medium, using $30 \mathrm{~mL} / \mathrm{g}$ of tissue, for $4 \mathrm{~d}$ under $5 \% \mathrm{O}_{2}, 5 \% \mathrm{CO}_{2}, 90 \%$ $\mathrm{N}_{2}$. In order to remove tissue debris and waste products, conditioned medium was filtered through a $70 \mu \mathrm{m}$ cell strainer, concentrated in Amicon Ultra- 15 centrifugal filter devices (MW: 3,000 kDa; Millipore, Billerica, MA, USA), re-suspended in fresh plain medium (hgDMEM $+1 \%$ $\mathrm{P} / \mathrm{S}$ ) in volume equal to the initial volume filtered (final concentration: $1 \mathrm{x}$ ), and filter sterilised. NCCM was then aliquoted and stored at $-80{ }^{\circ} \mathrm{C}$ until use.

\section{Cell seeding and culture}

Groups and culture conditions are presented in Table 1. NPCs and BMSCs alone were seeded at 3 million cells/ 
Table 1. Experimental groups. Bovine BMSCs and NPCs and porcine NCs were seeded in alginate beads in the indicated concentrations. Cells were then cultured for 28 d at $5 \% \mathrm{O}_{2}$ under the indicated culture medium conditions. $n=4$ for each cell group and medium.

\begin{tabular}{|c|c|c|c|c|}
\hline & NPC & $\mathrm{NPC}+\mathrm{NC}$ & NPC+ BMSC & BMSC \\
\hline Basal & $3 \times 10^{6}$ cells $/ \mathrm{mL}$ & $\begin{array}{c}3 \times 10^{6} \text { cells } / \mathrm{mL} \\
+ \\
3 \times 10^{6} \text { cells } / \mathrm{mL}\end{array}$ & $\begin{array}{c}3 \times 10^{6} \text { cells } / \mathrm{mL} \\
+ \\
3 \times 10^{6} \text { cells } / \mathrm{mL}\end{array}$ & $3 \times 10^{6}$ cells $/ \mathrm{mL}$ \\
\hline NCCM & $3 \times 10^{6}$ cells $/ \mathrm{mL}$ & $\mathrm{x}$ & $\begin{array}{c}3 \times 10^{6} \text { cells } / \mathrm{mL} \\
+ \\
3 \times 10^{6} \text { cells } / \mathrm{mL}\end{array}$ & $3 \times 10^{6}$ cells $/ \mathrm{mL}$ \\
\hline Chond & $3 \times 10^{6}$ cells $/ \mathrm{mL}$ & $\mathrm{x}$ & $\begin{array}{c}3 \times 10^{6} \text { cells } / \mathrm{mL} \\
+ \\
3 \times 10^{6} \text { cells } / \mathrm{mL}\end{array}$ & $3 \times 10^{6}$ cells $/ \mathrm{mL}$ \\
\hline
\end{tabular}

$\mathrm{mL}$ into alginate beads (Guo et al., 1989). NPCs and BMSCs (NPC + BMSC) as well as NPCs and NCs (NPC + NC) were mixed 1:1 (Gantenbein-Ritter and Chan, 2012; Watanabe et al., 2010) and seeded at a final concentration of 6 million cells $/ \mathrm{mL}$. Beads were then cultured according to Table 1 with Basal medium (Basal): plain medium (hgDMEM $+1 \% \mathrm{P} / \mathrm{S})$ with serum-free supplements [1\% ITS- $1^{+}$(BD Bioscience, Breda, The Netherlands) $+1.25 \mathrm{mg} / \mathrm{mL}$ bovine serum albumin (Roche) $+50 \mu \mathrm{g} /$ $\mathrm{mL}$ ascorbic acid 2-phosphate (Sigma, Zwijndrecht, the Netherlands) $+40 \mu \mathrm{g} / \mathrm{mL}$ L-proline (Sigma) $+100 \mu \mathrm{g} /$ $\mathrm{mL}$ sodium pyruvate (Gibco)]; NC conditioned medium (NCCM); conditioned medium supplemented with serumfree supplements; and chondrogenic medium (Chond): Basal medium $+0.1 \mu \mathrm{M}$ dexamethasone (Sigma) $+10 \mathrm{ng} /$ mL TGF 33 (Peprotech, Rocky Hill, NJ, USA). All medium supplements were added just prior to medium use. Beads were cultured for 4 weeks under $5 \% \mathrm{O}_{2}, 5 \% \mathrm{CO}_{2}, 90 \%$ $\mathrm{N}_{2}$, with 4 independent samples for each cell group and medium condition.

\section{Cell viability and morphology}

At day 1 and 28, beads ( 2 beads/independent sample) were washed and incubated in $10 \mu \mathrm{M}$ calcein green (Sigma) $/ 10 \mu \mathrm{M}$ propidium iodide (Molecular Probes; Carlsbad, CA, USA) solution for $1 \mathrm{~h}$ at $37{ }^{\circ} \mathrm{C}$. Cells were then imaged at a depth of $100 \mu \mathrm{m}$ using a confocal microscope (CLSM 510 Meta; Zeiss, Sliedrecht, the Netherlands). At day 1, only beads in Basal medium were analysed. At day 0 and 28, (2 beads/independent sample; for NPC + NC group only) were fixed in $3.7 \%$ buffered formalin overnight at $4{ }^{\circ} \mathrm{C}$ and embedded in paraffin. $10 \mu \mathrm{m}$ thick sections were cut and stained with Mayer's haematoxylin (Sigma) and eosin Y (Sigma) (HE) staining. Stained sections were dehydrated before mounting in Entellan (Merck, Darmstadt, Germany) and observed with a bright field microscope (Observer Z1; Zeiss).

Cell proliferation and cartilaginous matrix formation At days 0 and 28, 5 beads/independent sample were pooled and digested in papain solution at $60{ }^{\circ} \mathrm{C}$ for $16 \mathrm{~h}$ (Potier and Ito, 2013). Sulphated glycosaminoglycan (GAG) content was determined with the dimethyl methylene blue assay adapted for alginate presence (Enobakhare et al.,
1996), as a measure of proteoglycans. Standards were also digested with empty alginate beads to maintain an alginate concentration identical for references and experimental samples. Hydroxyproline (HYP), representative of the collagen content, was measured using the Chloramine- $T$ assay (Huszar et al., 1980). DNA content, as a measure of cell number, was measured using the Quant-iT⿱一土 PicoGreen ${ }^{\circledR}$ dsDNA assay kit (Invitrogen; Carlsbad, CA, USA) following manufacturer's instructions. At day 28, beads ( 2 beads/independent sample) were fixed in $3.7 \%$ buffered formalin overnight at $4{ }^{\circ} \mathrm{C}$ and embedded in paraffin. $10 \mu \mathrm{m}$ thick sections were cut and stained in Alcian Blue solution (Sigma; $1 \%, \mathrm{pH} 1.0$ for alginate presence) for $30 \mathrm{~min}$ at room temperature. Sections were then rinsed in $0.1 \mathrm{M} \mathrm{CaCl}_{2}$, and counter-stained with haematoxylin for $10 \mathrm{~min}$ at room temperature. Stained sections were dehydrated, mounted in Entellan, and observed with a bright field microscope.

\section{Gene expression}

At day 0 and 28, 5-8 beads/independent sample were pooled and depolymerised in $55 \mathrm{mM}$ sodium citrate, $0.15 \mathrm{M}$ sodium chloride, $0.60 \mathrm{~g}$ HEPES ( $\mathrm{pH} 7.4$ ). Released cells were pelleted and re-suspended in RLT buffer (Qiagen, Venlo, The Netherlands) to lyse them. Cell lysates were kept at $-80{ }^{\circ} \mathrm{C}$ until further extraction using the RNeasy ${ }^{\circledR}$ mini-kit (Qiagen) with an on-column DNAse digestion step. Quantity and purity of isolated RNA were measured by spectrophotometry (ND-1000; Isogen, De Meern, The Netherlands) and integrity by gel electrophoresis. $100 \mathrm{ng}$ of total RNA were then reverse transcribed (Superscript ${ }^{\circledR} V$ Vilo $^{\mathrm{TM}}$; Invitrogen). Gene expression levels of type II collagen (COL2A1), aggrecan (ACAN), SRY (sex determining region Y)-box 9 (SOX9), and type I collagen (COL1A1) were assessed with qPCR (CFX384 ${ }^{\mathrm{TM}}$; Biorad, Hercules, CA, USA) using $0.15 \mathrm{ng}$ cDNA/well with $\mathrm{iQ}^{\mathrm{TM}} \mathrm{SYBR}{ }^{\circledR}$ green supermix (Biorad) (see Table 2 for primer list). Primers were designed from bovine sequences, but were tested positive for cross-reactivity with porcine material. $18 \mathrm{~S}$ was selected as the reference gene as it was the most stable gene throughout our experimental conditions from four tested genes: hypoxanthine phosphoribosyltransferase 1 (HPRT1), glyceraldehyde-3phosphate dehydrogenase (GAPDH), actin beta (ACTB) 
Table 2. Primer sequences for target and reference genes used in RT-qPCR assays.

\begin{tabular}{|c|c|c|c|c|}
\hline Gene $^{\mathrm{a}}$ & Accession Gene ${ }^{b}$ & Sequence 5'-3' & Product size (bp) & Source $^{\mathrm{c}}$ \\
\hline \multirow[t]{2}{*}{ GAPDH } & NM_001034034 & GGCGTGAACCACGAGAAGTATAA & 119 & (Robinson et al., 2007) \\
\hline & & CCCTCCACGATGCCAAAGT & & \\
\hline \multirow[t]{2}{*}{$18 \mathrm{~S}$} & NR_036642 & CGGACAGGATTGACAGATTGAT & 117 & PD \\
\hline & & CCAGAGTCTCGTTCGTTATCG & & \\
\hline \multirow[t]{2}{*}{ HPRT1 } & AF176419 & TGCTGAGGATTTGGAGAAGG & 154 & (Goossens et al., 2005) \\
\hline & & CAACAGGTCGGCAAAGAACT & & \\
\hline ACTB & NM_173979 & Not available & Not available & PD \\
\hline \multirow[t]{2}{*}{ COL2A1 } & NM_001001135 & CCAGCGTCCCCAAGAAGA & 114 & $\mathrm{PD}$ \\
\hline & & CCAGGTTGTCATCTCCATAGC & & \\
\hline \multirow[t]{2}{*}{ ACAN } & NNM_173981 & CCAACGAAACCTATGACGTGTACT & 107 & (Zeiter et al., 2009) \\
\hline & & GCACTCGTTGGCTGCCTC & & \\
\hline \multirow[t]{2}{*}{ SOX9 } & AF278703 & ACGCCGAGCTCAGCAAGA & 70 & (Shintani et al., 2007) \\
\hline & & CACGAACGGCCGCTTCT & & \\
\hline \multirow[t]{2}{*}{ COL1A1 } & NM_001034039 & GACTGTAATAACGCCAAAGT & 82 & $\mathrm{PD}$ \\
\hline & & TTTCTTGGTCCGTGGGTGAT & & \\
\hline
\end{tabular}

${ }^{a}$ GAPDH, glyceraldehyde-3-phosphate dehydrogenase; 18S, 18S ribosomal RNA; HPRT1, hypoxanthine phosphoribosyltransferase 1; ACTB: actin, beta; COL2A1, collagen type II alpha 1; ACAN, aggrecan; SOX9, SRY (sex determining region Y)-box 9; COL1A1, collagen type I alpha 1.

${ }^{\mathrm{b}}$ The accession number is the GenBank ${ }^{\mathrm{TM}}$ accession number. ${ }^{\mathrm{C}} \mathrm{PD}$ : primers designed by and ordered from Primerdesign Ltd (Southampton, UK).

and $18 \mathrm{~S}$ ribosomal RNA (18S). Expression of gene of interest is reported as relative to $18 \mathrm{~S}$ expression and normalised to Day 0 expression levels $\left(2^{-\Delta \Delta C t}\right.$ method) using efficiency-corrected comparative quantitation (Pfaffl, 2001). Primer efficiency was determined in every PCR run. When gene expression was not detected, the $C_{t}$ value was set to 40 to conduct the statistical analysis.

\section{Statistical analysis}

All statistical analyses were performed using Microsoft ${ }^{\circledR}$ Excel 2010/XLSTAT ${ }^{\odot}$-Pro (version 2013.3.05; Addinsoft Inc., Brooklyn, NY, USA). General linear regression models based on ANOVAs were used to examine the effects of "cell type", "culture medium", and "day of culture" and their interactions on the DNA content and gene expression variables, and the effects of "cell type" and "culture medium" and their interaction on the GAG and HYP content data. Full factorial models were fitted to the data and then a backwards-stepwise procedure was used to remove the non-significant effects. For each significant effect, a LSD-Fisher post-hoc test was conducted. A $p$-value $<0.05$ was considered significant. The data were analysed with all cell, medium (and time) conditions combined in order to increase the power of the test and minimise the probability of declaring a difference that does not exist.

\section{Results}

Exposure to molecular factors secreted by NCs: culture of NPCs under NCCM

At day 1, NPCs displayed good cell survival and appeared well dispersed (Fig. 1a). At day 28, NPCs survived in all medium conditions, with formation of aggregates mainly for NCCM and Chondrogenic medium (Fig. 1a). Accordingly, DNA content only increased for NCCM and Chondrogenic medium (Fig. 5). Culture of NPCs under NCCM or Chondrogenic medium also promoted the production of proteoglycans (GAG/bead: 3.9 and $3.4 \mathrm{x}$ Basal medium, respectively; Fig. 6a). This augmentation was not only caused by an increase in the number of producing cells but also by a higher GAG synthesis at the cell level (GAG/DNA; Fig. 6b). NCCM stimulation of NPCs led to GAG production similar to NPC + BMSC in Basal medium, both overall and at cell level (Fig. 6). Proteoglycans were mainly deposited around and within the aggregates formed by proliferating NPCs (Fig. 1b). Collagens were barely detected in all NPC groups (with a measured maximum of $0.08 \mu \mathrm{g} /$ bead; data not shown). The levels of expression of aggrecan, type II collagen, and SOX9 were not influenced by the medium used during cell culture and, except for SOX9, were similar to NPC + BMSC (Fig. 7). Their expression, however, slightly, but 
Fig. 1. Culture of NPCs under Basal, NCCM or Chondrogenic medium: cell viability and proteoglycan deposition. (a) Cell viability at day 1 and after $28 \mathrm{~d}$ of culture in basal medium, NCCM, or chondrogenic medium with calcein staining for living cells (green) and propidium iodide staining for dead cells (red). Scale bar is $100 \mu \mathrm{m}$. (b) Alcian Blue staining after $28 \mathrm{~d}$ of culture in basal medium, NCCM, or chondrogenic medium. Scale bars are $100 \mu \mathrm{m}$ and $10 \mu \mathrm{m}$. Note that light blue is alginate.

a.
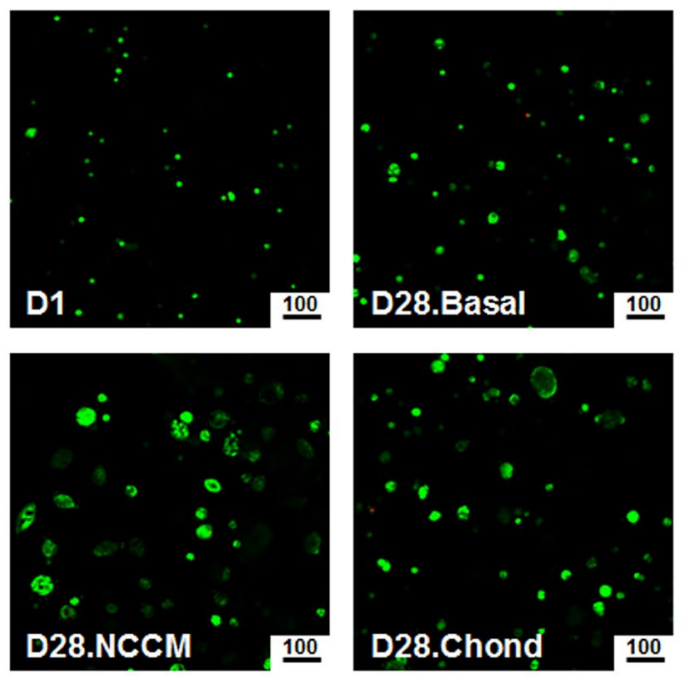

b.
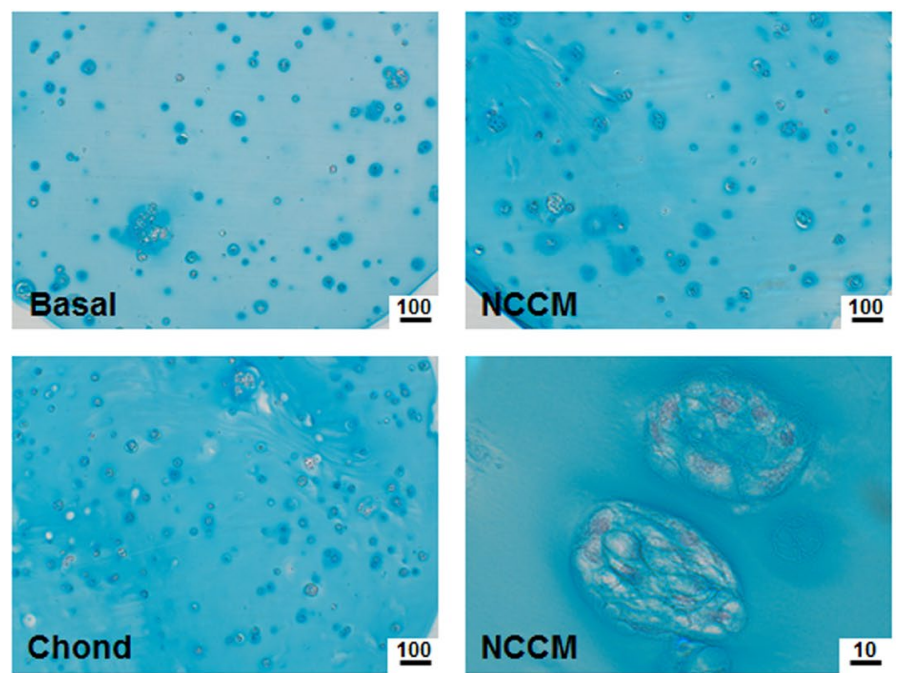

a.
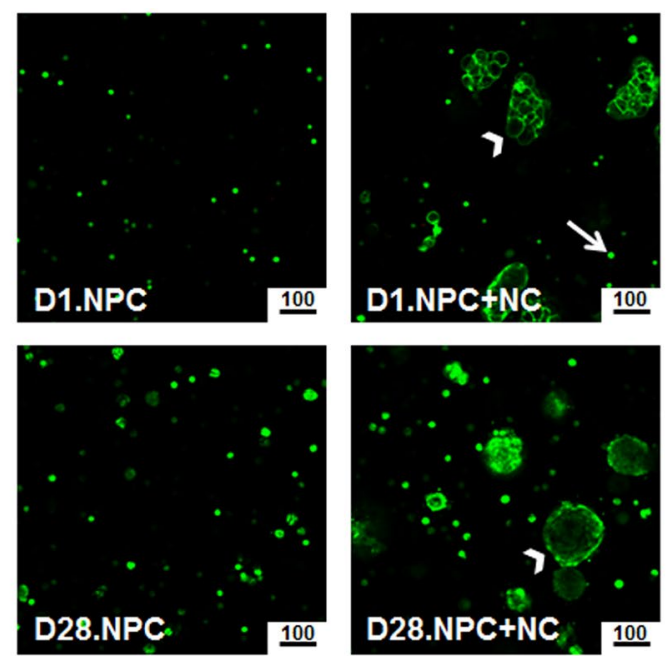

b.
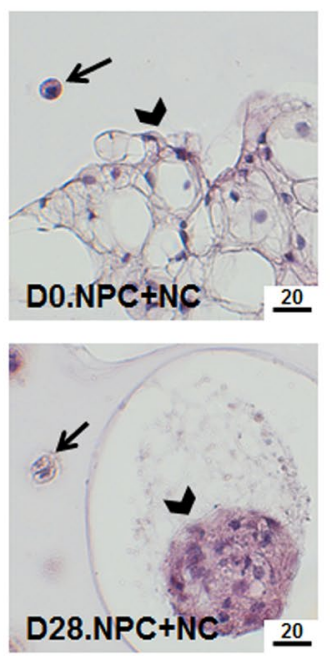

c.
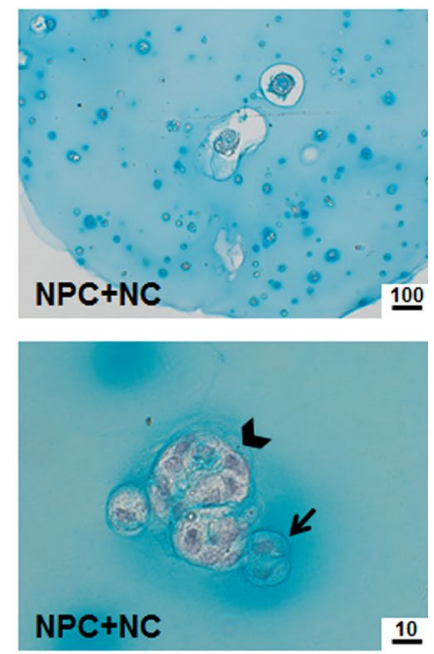

Fig. 2. Direct NPC + NC co-culture under Basal medium: cell viability, cell morphology and proteoglycan deposition. (a) Cell viability at day 1 and after $28 \mathrm{~d}$ of culture in basal medium with calcein staining for living cells (green) and propidium iodide staining for dead cells (red). Scale bar is $100 \mu \mathrm{m}$. (b) HE staining at day 0 and 28 for NPC + NC. Scale bar is $20 \mu \mathrm{m}$. (c) Alcian Blue staining for NPC $+\mathrm{NC}$ after $28 \mathrm{~d}$ of culture in basal medium. Scale bars are $100 \mu \mathrm{m}$ and $10 \mu \mathrm{m}$. Note that light blue is alginate. Arrow: NPCs; chevron: clustered NCs. 
Fig. 3. Direct NPC + BMSC co-culture under Basal, NCCM and Chondrogenic medium: cell viability and proteoglycan deposition. (a) Cell viability at day 1 and after $28 \mathrm{~d}$ of culture in basal medium, NCCM, or chondrogenic medium with calcein staining for living cells (green) and propidium iodide staining for dead cells (red). Scale bar is $100 \mu \mathrm{m}$. (b) Alcian Blue staining after $28 \mathrm{~d}$ of culture in basal medium, NCCM, or chondrogenic medium. Scale bars are $100 \mu \mathrm{m}$ and $10 \mu \mathrm{m}$. Note that light blue is alginate. a.
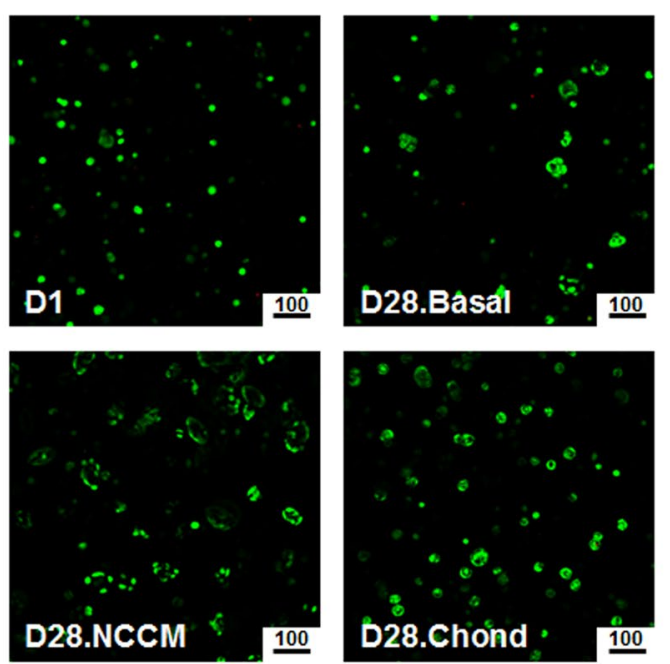

b.
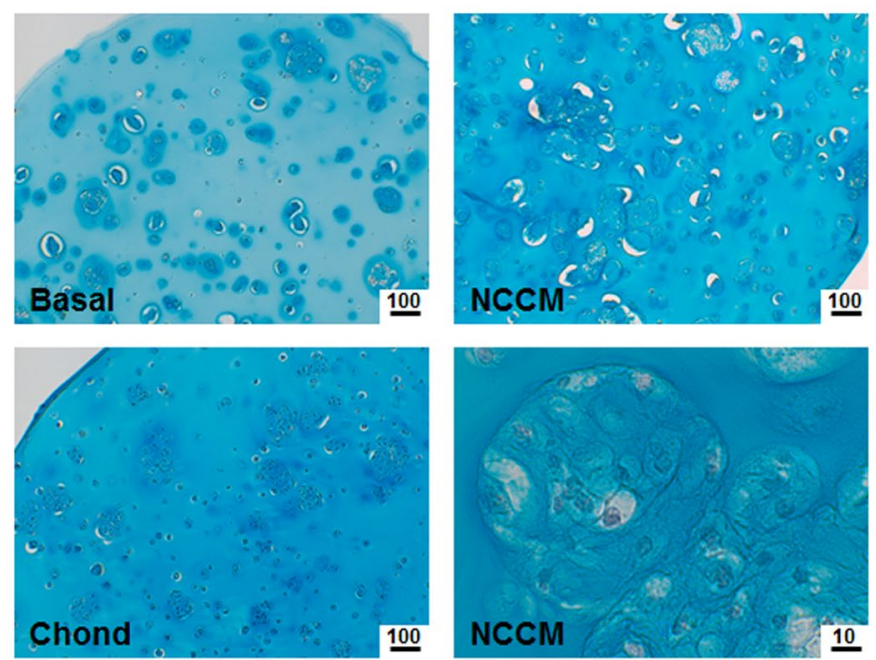

not significantly, decreased at day 28 (0.04-0.71 x Day $0)$. Type I collagen was not influenced by time or medium composition for the NPC groups.

\section{Addition of a potential NPC-like cell source: direct NPC + NC co-culture}

Both NPCs (small, round cells) and NCs (vacuolated, clustered cells) showed good cell survival at day 1 (Fig. 2a). At day 28, NCs lost their vacuoles and reduced in size compared to day 1 (Fig. 2a), which was confirmed by the qualitative assessment of the HE stained cells (Fig. 2b). Addition of NCs did not promote cell proliferation with DNA content remaining similar to day 0 values (Fig. 5).

Compared to NPCs cultured under Basal medium, $\mathrm{NPC}+\mathrm{NC}$ did not increase the proteoglycan production, overall (GAG/bead) or at the cell level (GAG/DNA) (Fig. 6). Moreover, GAG content was significantly lower than for NPC + BMSC cultured with Basal Medium (7.9 and $28.6 \mu \mathrm{g} /$ bead, respectively). Alcian blue staining revealed that more proteoglycans were deposited around small aggregates of NPCs than within clustered NCs (Fig. 2c). Gene expression of type I and II collagens, aggrecan, and SOX9 was similar to NPC + BMSC (Fig. 7). HYP was also only detected at very low levels $(0.05 \mu \mathrm{g} / \mathrm{bead}$; data not shown).
Addition of regenerative cells with or without exposure to molecular factors secreted by NCs: direct NPC + BMSC co-culture under Basal medium and $\mathrm{NCCM}$

$\mathrm{NPC}+$ BMSC showed good cell viability at day 1 (Fig. $3 a)$. At day 28, cells proliferated and aggregated in all groups, with large structures formed under NCCM and Chondrogenic medium (Fig. 3a). DNA measurements confirmed that cells proliferated in all groups, with Chondrogenic medium giving the highest cell content (Fig. 5). GAG synthesis was also high in all groups: NPC + BMSC under Basal medium already produced $28.6 \mu \mathrm{g} / \mathrm{bead}$ (Fig. 6a). Culture under NCCM and Chondrogenic medium further enhanced this proteoglycan production, with higher values for chondrogenic conditions than for NCCM (56.0 and $42.2 \mu \mathrm{g} / \mathrm{bead}$, respectively). These increases, however, are mostly due to the proliferation of producing cells (1.9$2.6 \times$ Day 0) rather than an improved GAG production at the cell level (GAG/DNA), which remains similar to NPCs under NCCM (76.4 $\mu \mathrm{g} / \mu \mathrm{g}$ DNA; Fig. 6b) for all medium conditions. Alcian blue staining validated the overall beneficial effects of NCCM and Chondrogenic medium, with proteoglycan deposition not only around proliferating cells but throughout the alginate scaffold (Fig. 3b). Gene expression of all analysed disc proteins 
Fig. 4. BMSCs under Basal, NCCM and Chondrogenic medium: cell viability and proteoglycan deposition. (a) Cell viability at day 1 and after $28 \mathrm{~d}$ of culture in basal medium, NCCM, or chondrogenic medium with calcein staining for living cells (green) and propidium iodide staining for dead cells (red). Scale bar is $100 \mu \mathrm{m}$. (b) Alcian Blue staining after $28 \mathrm{~d}$ of culture in basal medium, NCCM, or chondrogenic medium. Scale bars are $100 \mu \mathrm{m}$ and $10 \mu \mathrm{m}$. Note that light blue is alginate.

a.
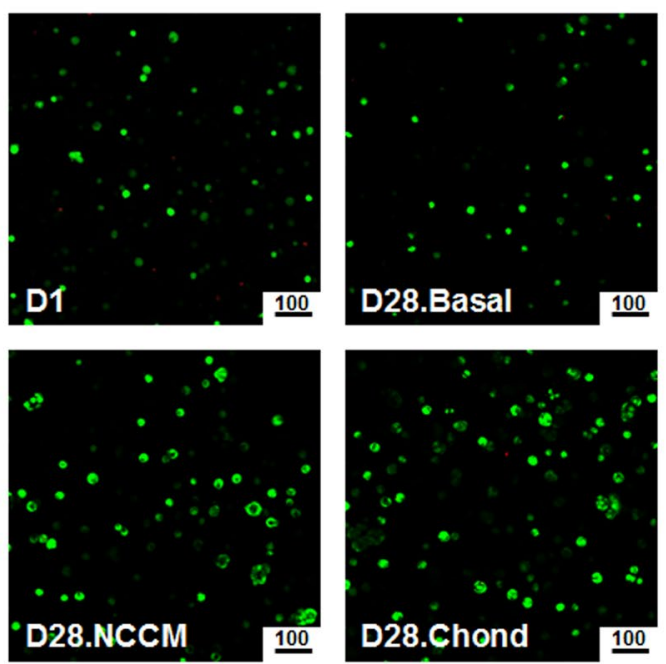

b.
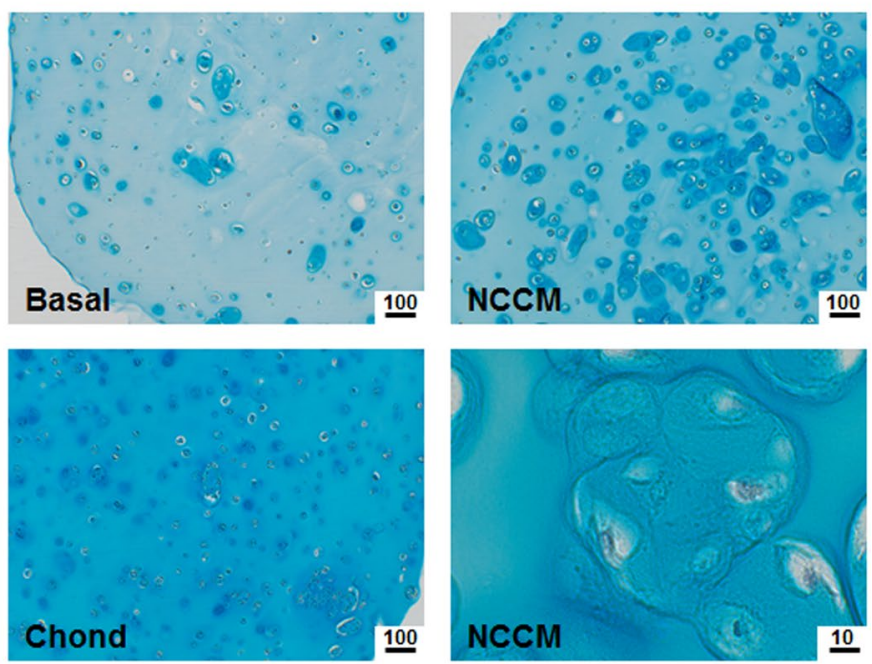

Fig. 5. Cell proliferation. DNA content $(\mu \mathrm{g})$ per bead at day 0 and day 28 . Values are mean \pm standard deviation. $n=4$ per group. $a$ : $p<0.05$ for "cell type" main effect with al different from "NPC" and a2 different from "NPC + BMSC"; $b$ : $p<0.05$ for "cell type" $\mathrm{x}$ "day of culture" interaction; $c: p<0.05$ for "culture medium" $\mathrm{x}$ "day of culture" interaction with $c l$ different from "NCCM" $x$ "D28" and c2 different from "Chond" $\mathrm{x}$ "D28".

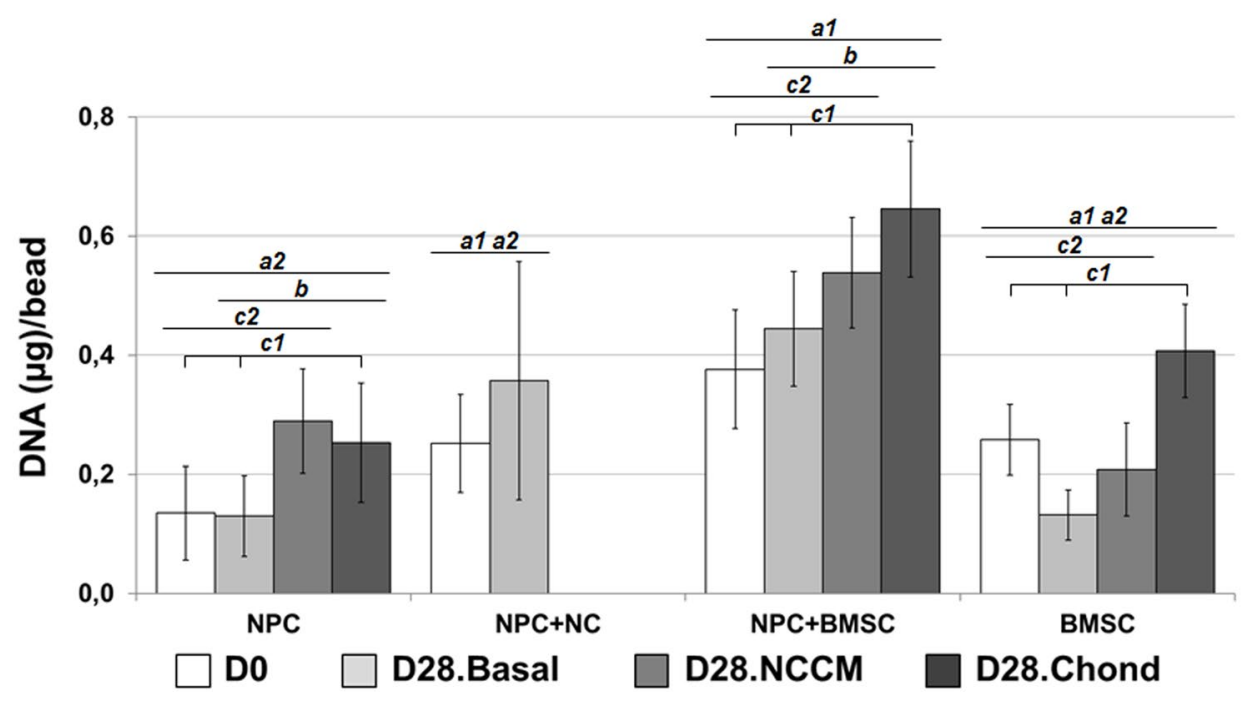

was, again, unaffected by medium conditions. Although gene expression levels (1.94-11.47 x Day 0) and collagen contents $(0.66-0.94 \mu \mathrm{g} / \mathrm{bead})$ were higher than for NPCs, no statistical differences were found to NPC + BMSC Day 0 or Day 28 NPC values (Fig. 7), except for SOX9.

\section{Priming regenerative cells: BMSCs under NCCM} culture

As for all other groups, cell viability at day 1 was good and BMSCs were well dispersed (Fig. 4a). At day 28, cell viability remained good in all groups, though cell density decreased under Basal medium (Fig. 4a). These 
Fig. 6. Matrix production. GAG $(\mu \mathrm{g})$ (a) per bead and (b) per DNA $(\mu \mathrm{g})$ at day 28. Values are mean \pm standard deviation. $n=4$ per group. $a: p<0.05$ for "cell type" main effect with al different from "NPC" and $a 2$ different from "NPC + BMSC"; $d: p<0.05$ for "cell type" $\mathrm{x}$ "culture medium" interaction with d1 different from "NPC or $\mathrm{NPC}+\mathrm{BMSC} " \mathrm{x}$ "Basal" and $d 2$ different from "NPC + BMSC or BMSC" $\mathrm{x}$ "Chond"; $e: p<0.05$ for "culture medium" main effect with $e 1$ different from "Basal" and e2 different from "Chond".
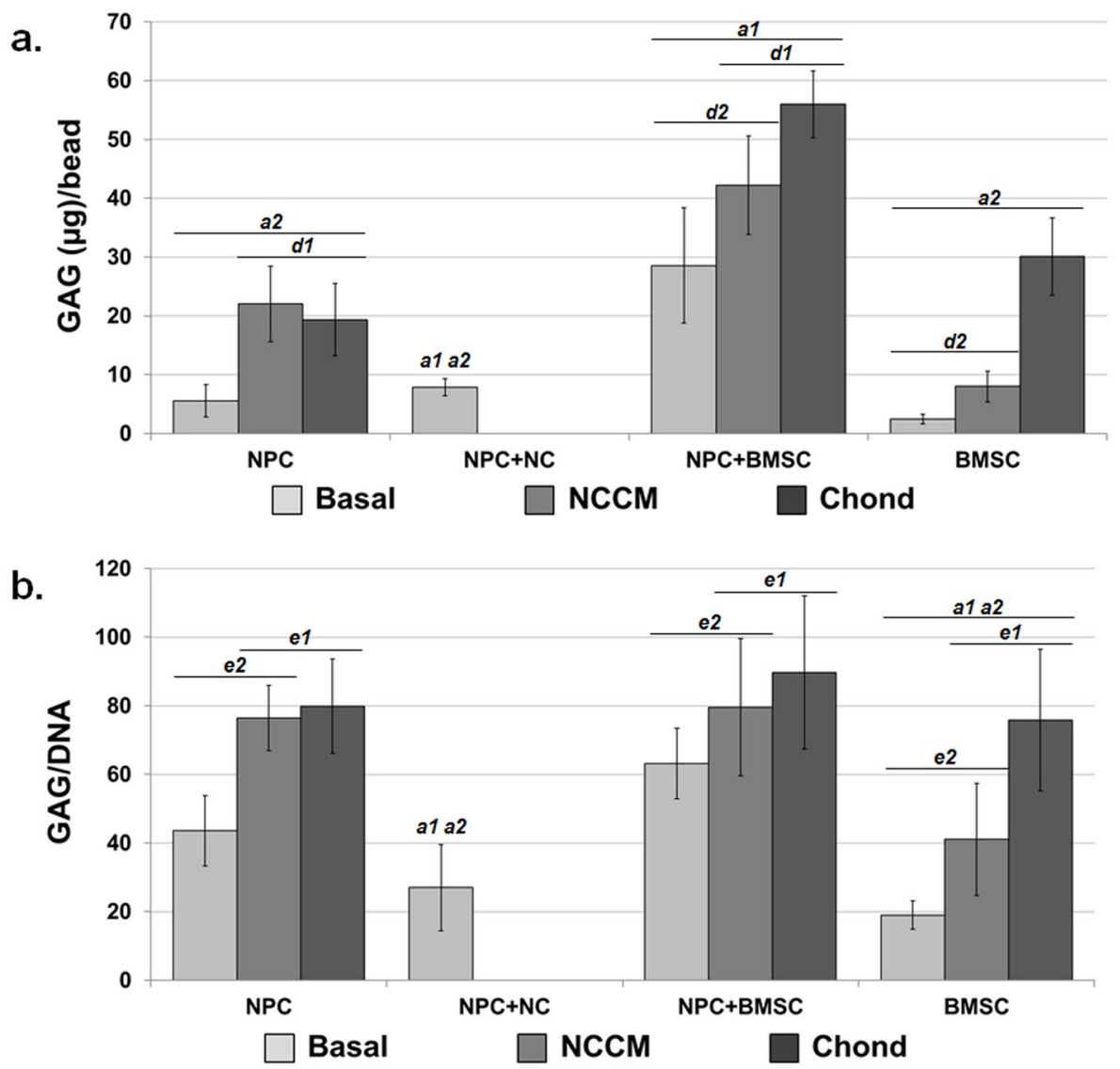

observations were confirmed by the DNA measurements (Fig. 5), with cell proliferation only observed for Chondrogenic medium (1.58 x Day 0). GAG content per bead was much lower than for NPC or NPC + BMSC groups for both Basal medium and NCCM (2.4 and $8.0 \mu \mathrm{g}$ / bead, respectively). Only culture under Chondrogenic medium led to high proteoglycan production $(30.1 \mu \mathrm{g} / \mathrm{bead}$; Fig. 6a). Similar trends were noted with GAG/DNA (Fig. 6b). Alcian blue staining also showed that Chondrogenic medium was much more effective to promote proteoglycan synthesis by BMSCs than Basal or NCCM media (Fig. 4b). Although medium conditions did not affect gene expression levels of aggrecan, type II collagen, and SOX9, these genes were highly amplified after 28 d of culture (4-145,449 x Day 0; Fig. 7). Type I collagen was not influenced by cell culture. Collagen content remained low (0.23-0.73 $\mu \mathrm{g} /$ bead; data not shown).

\section{Discussion}

NCs have already shown promising potential for intervertebral disc repair but the question remains what approach is the most efficient to promote disc matrix formation. This study indicates that NCs could stimulate both resident (NPCs) and regenerative (BMSCs) disc cells via secreted factors. The direct use of NCs, however, appears more limited.
When used as stimulators (NCCM), NCs could increase both proliferation and matrix production of NPCs to levels similar to a standard TGF $\beta$ stimulation (Figs. 5 and 6). Our data confirm, in a long term study (4 weeks), that bioactive factors secreted by NCs stimulate proteoglycan synthesis by NPCs (GAG/DNA: $1.8 \times$ Basal), and to levels comparable to those reported in short term (1-2 weeks) studies with porcine NCs and human or bovine NPCs [2.0 x (Abbott et al., 2012) and $1.4 \mathrm{x}$ (Gantenbein-Ritter and Chan, 2012) Basal, respectively]. Contrary to the present study, however, NCCM appears to be more potent than chondrogenic medium (TGF $\beta_{3}$ and dexamethasone) for human cells (Abbott et al., 2012). The lack of sensitivity of human NPCs to chondrogenic stimulation may explain this discrepancy, as the GAG/DNA was lower for TGF $\beta$ stimulation than for basal conditions (Abbott et al., 2012). The positive effect of NCCM observed here was not reflected at the gene level, as aggrecan and type II collagen expression remained the same for all medium conditions, which was also reported in the other studies (Abbott et al., 2012; Gantenbein-Ritter and Chan, 2012). The same discrepancy was observed for other cell culture conditions and cell types, and could be explained by the fact that NCCM or TGF $\beta$ provide an early stimulation of aggrecan that is no more observed at the time of analysis (day 28). Another possibility is that the production of proteoglycans other than aggrecan is promoted, e.g. decorin or lumican. The gene expression profile of NPCs, however, also 

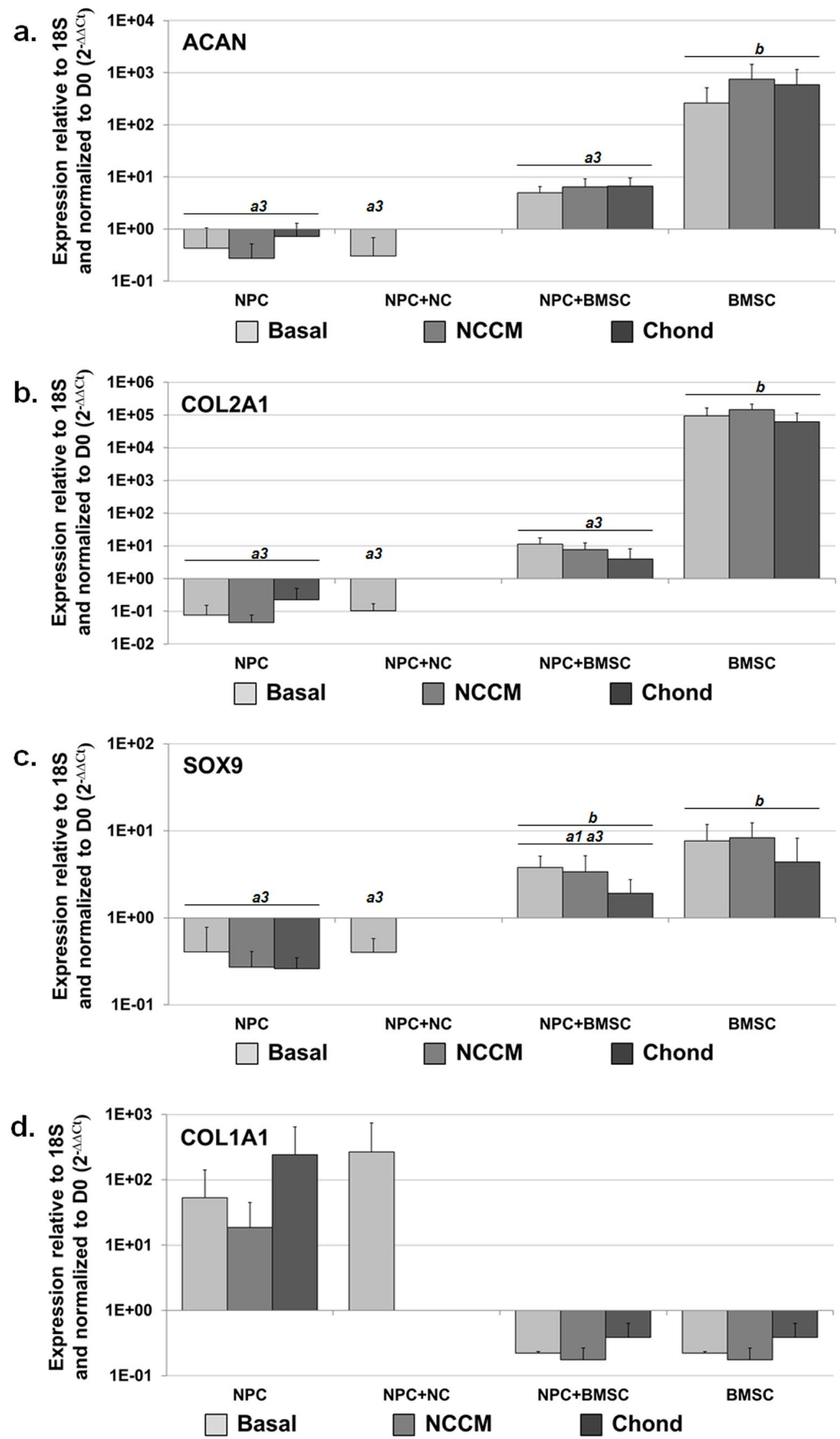

Fig. 7. Matrix protein gene expression. mRNA expression levels at day 28 of (a) aggrecan (ACAN), (b) type II collagen (COL2A1), (c) SRY (sex determining region Y)-box 9 (SOX9), and (d) type I collagen (COL1A1) relative to $18 \mathrm{~S}$ and normalised to day 0 levels (efficiency corrected $2^{-\Delta \Delta \mathrm{Ct}}$ method). Values are means + standard deviation. $n=4$ per group. Note the logarithmic scale. $a: p<0.05$ for "cell type" main effect with $a 1$ different from "NPC" and a3 different from "BMSC"; $b: p<0.05$ for "cell type" $\mathrm{x}$ "day of culture" interaction. 
showed a down-regulation of aggrecan, type II collagen and SOX9 and an up-regulation of type I collagen. Though these values were not statistically different from Day 0 due to high variations between donors, they reveal a slight de-differentiation of NPCs in our culture system, which may alter their response to culture conditions. The fact that freshly isolated NPCs are in an environment devoid of NP matrix, osmotic pressure and hydrostatic loading, when they are seeded in the alginate beads, may explain this de-differentiation. All of these environmental cues might, indeed, be needed to maintain the original NPC phenotype.

When used in direct NPC + NC co-culture, NCs did not substantially promote cell proliferation or matrix production (Figs. 5 and 6). The slight increase in GAG content suggests that NCs may produce low amounts of GAG, which is confirmed by the light deposition of proteoglycan around and within the clustered NCs. None the less, NCs did not appear as good replacements for NPCs, as the GAG/DNA was significantly lower for NPC + NC than for NPCs alone. This is contradictory to a previous study reporting a higher synthesis rate for canine NCs than for canine NPCs when cultured separately for $10 \mathrm{~d}$ in alginate (Cappello et al., 2006). This difference may be explained by the direct co-culture, with NPCs inhibiting the GAG synthesis by NCs. Another, more likely, explanation can also be the (de)differentiation of the NCs during the 4 weeks of culture: as the cells become smaller and lose their vacuoles (Fig. 2b), they also lose their higher ability to produce proteoglycans. The change of NC phenotype during the 4 weeks of culture, as demonstrated before in similar culture conditions (Ito et al., 2013), can also explain why the NCs did not act as stimulators in the direct coculture. This would then imply that the observed influence of NCCM may be intrinsic to freshly isolated NCs. The observed change of phenotype is most likely due to the culture conditions being inappropriate for NCs. High glucose concentration, for example, has been shown to decrease rat NC proliferation and increase their apoptosis (Park and Park, 2013). Although the concentration used here $(0.025 \mathrm{M})$ is lower than those tested by Park and Park $(0.1$ to $0.4 \mathrm{M})$, it may still be too high to maintain NC phenotype. Raised osmolarity (400 mOsm/kg vs. $323 \mathrm{mOsm} / \mathrm{kg}$ used here) has also been demonstrated to improve the phenotype of canine NCs (Spillekom et al., 2014). However, porcine NCs did not show such sensitivity to medium osmolarity, with the same expression levels of Brachyury, cytokeratins-8/-18/-19, aggrecan, and type II collagen at 330 or $400 \mathrm{mOsm} / \mathrm{kg}$ (Arkesteijn et al., 2013).

The "standard" addition of BMSCs to NPCs also led to a high matrix production (Fig. 6), with levels of synthesis (GAG/DNA) similar to NPCs though the co-culture started with $50 \%$ of undifferentiated cells (BMSCs). Although no statistical differences were found, the co-culture also tends to increase the gene expression of type II collagen and aggrecan (0.077 and $0.43 \times$ Day 0 for NPC vs. 11.47 and $4.96 \times$ Day 0 for NPC + BMSC, respectively). Starting with healthy fully differentiated NPCs can explain, at least in part, why high fold increases are not observed in the NPC, $\mathrm{NPC}+\mathrm{NC}$, and NPC + BMSC groups for type II collagen, SOX9, and aggrecan expressions, contrary to the BMSCs. These proteins are already highly expressed at day 0 in fully differentiated cells such as NPCs or NCs, contrary to undifferentiated BMSCs, and can only be further stimulated to a certain extent. The expression levels for NPC + BMSC are then an average of the slightly decreasing expressions in NPCs and highly up-regulated ones in BMSCs. The observation that type I collagen in NPC + BMSC is similar to BMSCs and not an average value of NPC/BMSC levels suggests that BMSCs are able to, at least partially, limit the de-differentiation of NPCs. These positive effects have already been reported in previous studies using human cells in 2D culture (Richardson et al., 2006; Strassburg et al., 2010) or 3D pellet systems (Sobajima et al., 2008) and may be caused by stimulation of NPCs by BMSCs (Richardson et al., 2006) or by the promotion of BMSC differentiation (Richardson et al., 2006; Strassburg et al., 2010), via the formation of tunnelling nanotubes (Lehmann et al., 2014). Unfortunately, the culture system used in the present study did not allow the distinction between NPCs and BMSCs, making it difficult to conclude whether NPCs or BMSCs are stimulated. The disc matrix formation by $\mathrm{NPC}+\mathrm{BMSC}$ could be further enhanced by culture under NCCM or Chondrogenic medium, mostly by increased proliferation of producing cells, the GAG/DNA not being strongly affected by the medium condition. The increase of matrix production under NCCM culture, however, was moderate compared to the one of NPCs alone (GAG/bead: 1.47 and $3.94 \mathrm{x}$ Basal, respectively). The strong stimulation of NPCs and BMSCs by each other, making these cells less sensitive to an additional incentive, may explain this lower level of stimulation as BMSCs alone could also respond strongly to NCCM.

Indeed, NCCM promoted proliferation and matrix production of BMSCs as well (Figs. 5 and 6). Though these increases were important, Chondrogenic medium led to a much stronger response from BMSCs. This higher reaction to chondrogenic medium is contradictory to previous reports with human BMSCs (Korecki et al., 2010; Purmessur et al., 2011). NCCM, however, led to the same extent of stimulation of matrix synthesis for both human and bovine cells [GAG/DNA: 2.4 and $1.6 \times$ Basal (Korecki et al., 2010; Purmessur et al., 2011) and $2.2 \mathrm{x}$ Basal, respectively]. It suggests, again, that human cells may be less sensitive to TGF $\beta$ stimulation instead of bovine cells being less responsive to NCCM. BMSC differentiation was also confirmed at the gene level, with aggrecan and type II collagen highly up-regulated under all culture conditions (Fig. 7). Although the fact that Chondrogenic medium did not lead to a higher up-regulation of the analysed genes than the Basal medium may seem surprising, spontaneous differentiation of bovine BMSCs in 3D culture has already been reported (Bosnakovski et al., 2006; Potier et al., 2014). The higher production of proteoglycans for NCCM and Chondrogenic medium, however, suggests a faster up-regulation of these genes than for Basal medium. However, the lack of intermediate time points did not allow confirmation of this hypothesis.

One limitation of the present study is the in vitro approach used, where isolated cells are seeded into alginate and cultured under standard culture media. Cells are then out of their native tissue which can provide cues, through cell-matrix interactions, that may alter cells' response to 
stimulation. The culture system did not include the disc environmental factors, such as low $\mathrm{pH}$ or high osmolarity, showed to affect cell behaviour, especially that of BMSCs (Wuertz et al., 2008). Another limitation may be the use of a cross-species model. This approach, however, has already led to successful stimulation of bovine (Gantenbein-Ritter and Chan, 2012) and human (Korecki et al., 2010; Purmessur et al., 2011) cells by porcine NCs. Though these results support an interspecies potential of NCCM, its effect could be more potent if NC tissue, NPCs and BMSCs were obtained from the same species. The canine model is then of particular interest as it offers the possibility to obtain NCs from non-chondrodystrophic breeds and NPCs from chondrodystrophic dogs. Increased proteoglycan production in the NPC + BMSC group can also be explained by the higher cell seeding concentration used for this group ( 6 million cells $/ \mathrm{mL})$ than for the NPCs alone ( 3 million cells $/ \mathrm{mL}$ ), favouring paracrine effects and cell-cell communication. The alginate beads seeded with NPCs were used here as a simplified model of NP tissue, where NPCs will be exposed to BMSC, NC and/or NCCM injection. Injecting cells in vivo in the disc will immediately increase the in situ cell concentration, as NPC density will remain the same. For this reason, the NPC concentration was maintained constant between the experimental groups, independent of the treatment applied.

Overall, the results demonstrated that NCCM could stimulate disc matrix production to a level similar to the addition of regenerative cells. Using NCCM, however, may be a more alluring clinical strategy for the repair of mildly degenerated discs. Indeed, in order to reach a 1:1 ratio of NPC:BMSC, as used here, it would require a massive injection of BMSCs. Furthermore, the use of BMSCs raises some concerns, as formation of osteophytes in vertebrae adjacent to the implantation site has been reported in a rabbit model (Vadala et al., 2012). In spite of these advantages, NCCM may not be enough for more severe cases of disc degeneration, as these are also characterised by a decreased number of NPCs. In such cases, BMSCs could then be used to complement the resident cell population, as they led to substantial production of proteoglycans and responded to NCCM. Unfortunately, the simultaneous use of NCCM and BMSCs did not result in a synergistic effect, probably due to the strong stimulative effect of the $\mathrm{NPC}+\mathrm{BMSC}$ co-culture, masking the weaker stimulation exerted by the NCCM. This conclusion, though, only stands for the NCCM concentration and the NPC:BMSC ratio tested here. The results may also be influenced by the final cell concentration used. Increasing or decreasing this concentration will affect the cell-cell interactions and paracrine effects by reducing or enlarging the distance between the cells._However, in order to observe such effects it may be required to drastically change the cell concentration. Bovine BMSCs seeded into alginate at 3 or 14 million cells $/ \mathrm{mL}$, indeed, displayed similar proteoglycan production at the cell level (GAG/DNA) (Potier et al., 2011). The cell concentration used here was chosen to be representative of the NP tissue where the NPC density has been measured at 3-5 million cells/mL (Maroudas et al., 1975).
NCCM per se, of course, is not suitable for clinical application, as it will require a large quantity of NC-rich tissue that can only be obtained from deceased young or foetal donors, as these cells disappear before 10 years old (Zhao et al., 2007) and cannot be harvested without damaging the disc. Isolation and identification of the soluble factors involved in NCCM's effects appear, therefore, as the only realistic therapeutical approach to exploit the potential of the NCs. The use of animal models can then help to identify the bioactive factors involved, such as the canine model with the chondrodystrophic breeds displaying spontaneous disc degeneration close to the human condition (Alini et al., 2008). The fact that NCCM was as effective as TGF $\beta$ for NPCs but not for BMSCs suggests that it may contain bioactive factors other than TGF $\beta$, more specific to disc cells. Growth and differentiation factor (GDF) 5, for example, has been shown to induce a more discogenic phenotype in BMSCs than TGF $\beta$ (Stoyanov et al., 2011). Another factor potentially involved in NCCM's effects is connective tissue growth factor (CTFG), where precursors have been detected in canine NCCM and the recombinant protein can stimulate aggrecan gene expression in bovine NPCs (Erwin et al., 2006). Identification of these factors will then allow the use of a higher concentration in order to amplify their effects not only on NPCs but also on BMSCs. These bioactive factors can then be administrated in clinics by simple injection or by the implantation of an injectable controlled release system, such as fibrin gel (Drinnan et al., 2010) or microspheres (Solorio et al., 2010; Park et al., 2009).

\section{Conclusions}

To conclude, this study showed than NCs secreted bioactive factors able to efficiently promote proliferation and matrix production of NPCs. With a direct comparison between the two approaches, it also demonstrated for the first time that these factors had similar effects to the "standard" injection of BMSCs. The present results therefore empower the interest of biomolecules secreted by NCs as a promising alternative for intervertebral disc repair, as their effects may be further amplified when they are identified.

\section{Acknowledgements}

This work was supported by AOSpine International through an AOSpine Research Network grant (SRN2011_11). The authors would like to thank R.R. Delcher for his help with statistical analysis, and B. van Dijk and R. Dittmar for their help with cell extraction. We wish to confirm that there are no known conflicts of interest associated with this publication and there has been no significant financial support for this work that could have influenced its outcome. 


\section{References}

Abbott RD, Purmessur D, Monsey RD, Iatridis JC (2012) Regenerative potential of TGFbeta3 + Dex and notochordal cell conditioned media on degenerated human intervertebral disc cells. J Orthop Res 30: 482-488.

Aguiar DJ, Johnson SL, Oegema TR (1999) Notochordal cells interact with nucleus pulposus cells: regulation of proteoglycan synthesis. Exp Cell Res 246: 129-137.

Alini M, Eisenstein SM, Ito K, Little C, Kettler AA, Masuda K, Melrose J, Ralphs J, Stokes I, Wilke HJ (2008) Are animal models useful for studying human disc disorders/degeneration? Eur Spine J 17: 2-19.

Antoniou J, Steffen T, Nelson F, Winterbottom N, Hollander AP, Poole RA, Aebi M, Alini M (1996) The human lumbar intervertebral disc: evidence for changes in the biosynthesis and denaturation of the extracellular matrix with growth, maturation, ageing, and degeneration. J Clin Invest 98: 996-1003.

Arkesteijn ITM, Potier E, Ito K (2013) Maintaining notochordal phenotype. Global Spine Congress 2013, Hong-Kong, China [Abstract].

Bosnakovski D, Mizuno M, Kim G, Takagi S, Okumur M, Fujinag T (2006) Gene expression profile of bovine bone marrow mesenchymal stem cell during spontaneous chondrogenic differentiation in pellet culture system. Jpn J Vet Res 53: 127-139.

Cappello R, Bird JL, Pfeiffer D, Bayliss MT, Dudhia J (2006) Notochordal cell produce and assemble extracellular matrix in a distinct manner, which may be responsible for the maintenance of healthy nucleus pulposus. Spine 31: 873-882.

Chen J, Yan W, Setton LA (2006) Molecular phenotypes of notochordal cells purified from immature nucleus pulposus. Eur Spine J 15: 303-311.

Drinnan CT, Zhang G, Alexander MA, Pulido AS, Suggs LJ (2010) Multimodal release of transforming growth factor-beta1 and the BB isoform of platelet derived growth factor from PEGylated fibrin gels. J Control Release 147: 180-186.

EnobakhareBO, BaderDL, LeeDA(1996)Quantification of sulfated glycosaminoglycans in chondrocyte/alginate cultures, by use of 1,9-dimethylmethylene blue. Anal Biochem 243: 189-191.

Erwin WM, Ashman K, O’Donnel O, Inman RD (2006) Nucleus pulposus notochord cells secrete connective tissue growth factor and up-regulate proteoglycan expression by intervertebral disc chondrocytes. Arthritis Rheum 54: 3859-3867.

Gantenbein-Ritter B, Chan SC (2012) The evolutionary importance of cell ratio between notochordal and nucleus pulposus cells: an experimental 3-D co-culture study. Eur Spine J 21: S819-S825.

Gilbert HT, Hoyland JA, Richardson SM (2013) Stem cell regeneration of degenerated intervertebral discs: current status (update). Curr Pain Headache Rep 17: 377.

Goossens K, Van PM, Van SA, Vandesompele J, Van ZA, Peelman LJ (2005) Selection of reference genes for quantitative real-time PCR in bovine preimplantation embryos. BMC Dev Biol 5: 27.
Guo JF, Jourdian GW, MacCallum DK (1989) Culture and growth characteristics of chondrocytes encapsulated in alginate beads. Connect Tissue Res 19: 277-297.

Henriksson HB, Svanvik T, Jonsson M, Hagman M, Horn M, Lindahl A, Brisby H (2009) Transplantation of human mesenchymal stems cells into intervertebral discs in a xenogeneic porcine model. Spine 34: 141-148.

Hiyama A, Mochida J, Iwashina T, Omi H, Watanabe T, Serigano K, Tamura F, Sakai D (2008) Transplantation of mesenchymal stem cells in a canine disc degeneration model. J Orthop Res 26: 589-600.

Huszar G, Maiocco J, Naftolin F (1980) Monitoring of collagen and collagen fragments in chromatography of protein mixtures. Anal Biochem 105: 424-429.

Ito K, van Dijk BGM, Potier E (2013) Can notochordal cells promote bone marrow derived stromal cell potential for intervertebral disc repair? 59 $9^{\text {th }}$ Annual Meeting of the Orthopaedic Research Society, San Antonio, USA [Abstract].

Katz JN (2006) Lumbar disc disorders and low-back pain: socioeconomic factors and consequences. J Bone Joint Surg Am 88: 21-24.

Kim JH, Deasy BM, Seo HY, Studer RK, Vo NV, Georgescu HI, Sowa GA, Kang JD (2009) Differentiation of intervertebral notochordal cells through live automated cell imaging system in vitro. Spine 34: 2486-2493.

Kon E, Muraglia A, Corsi A, Bianco P, Marcacci M, Martin I, Boyde A, Ruspantini I, Chistolini P, Rocca M, Giardino R, Cancedda R, Quarto R (2000) Autologous bone marrow stromal cells loaded onto porous hydroxyapatite ceramic accelerate bone repair in critical size defects of sheep long bones. J Biomed Mater Res 49: 328-337.

Korecki CL, Taboas JM, Tuan RS, Iatridis JC (2010) Notochordal cell conditioned medium stimulates mesenchymal stem cell differentiation toward a young nucleus pulposus phenotype. Stem Cell Res Ther 1: 18.

Lehmann TP, Filipiak K, Juzwa W, Sujka-Kordowska P, Jagodzinski PP, Zabel M, Glowacki J, Misterska E, Walczak M, Glowacki M (2014) Coculture of human nucleus pulposus cells with multipotent mesenchymal stromal cells from human bone marrow reveals formation of tunnelling nanotubes. Mol Med Rep 9: 574-582.

Maroudas A, Stockwell RA, Nachemson A, Urban J (1975) Factors involved in the nutrition of the human lumbar intervertebral disc: cellularity and diffusion of glucose in vitro. J Anat 120: 113-130.

Orozco L, Soler R, Morera C, Alberca M, Sanchez A, Garcia-Sancho J (2011) Intervertebral disc repair by autologous mesenchymal bone marrow cells: a pilot study. Transplantation 92: 822-828.

Park EY, Park JB (2013) Dose- and time-dependent effect of high glucose concentration on viability of notochordal cells and expression of matrix degrading and fibrotic enzymes. Int Orthop 37: 1179-1186.

Park JS, Na K, Woo DG, Yang HN, Park KH (2009) Determination of dual delivery for stem cell differentiation using dexamethasone and TGF-beta3 in/on polymeric microspheres. Biomaterials 30: 4796-4805.

Pfaffl MW (2001) A new mathematical model for relative quantification in real-time RT-PCR. Nucleic Acids Res 29: e45. 
Potier E, Ito K (2013) Using notochordal cells of developmental origin to stimulate nucleus pulposus cells and bone marrow stromal cells for intervertebral disc regeneration. Eur Spine J 23: 679-688.

Potier E, Ferreira E, Andriamanalijaona R, Pujol JP, Oudina K, Logeart-Avramoglou D, Petite H (2007) Hypoxia affects mesenchymal stromal cell osteogenic differentiation and angiogenic factor expression. Bone 40: 1078-1087.

Potier E, Rivron N, van Blitterswijk C, Ito K (2011) The role of cellular communication in bone marrow derived stromal cell chondrogenic differentiation. TERMIS EU 2011 Meeting, Granada, Spain [Abstract].

Potier E, Rivron NC, Van Blitterswijk CA, Ito K (2014) Micro-aggregates do not influence bone marrow stromal cell chondrogenesis. J Tissue Eng Regen Med [Epub ahead of print] doi: 10.1002/term.1887.

Purmessur D, Schek RM, Abbott RD, Ballif BA, Godburn KE, Iatridis JC (2011) Notochordal conditioned media from tissue increases proteoglycan accumulation and promotes a healthy nucleus pulposus phenotype in human mesenchymal stem cells. Arthritis Res Ther 13: R81.

Richardson SM, Walker RV, Parker S, Rhodes NP, Hunt JA, Freemont AJ, Hoyland JA (2006) Intervertebral disc cell-mediated mesenchymal stem cell differentiation. Stem Cells 24: 707-716.

Roberts S, Evans H, Trivedi J, Menage J (2006) Histology and pathology of the human intervertebral disc. J Bone Joint Surg Am 88: 10-14.

Robinson TL, Sutherland IA, Sutherland J (2007) Validation of candidate bovine reference genes for use with real-time PCR. Vet Immunol Immunopathol 115: 160-165.

Sakai D, Mochida J, Iwashina T, Hiyama A, Omi H, Imai M, Nakai T, Ando K, Hotta T (2006) Regenerative effects of transplanting mesenchymal stem cells embedded in atelocollagen to the degenerated intervertebral disc. Biomaterials 27: 335-345.

Shintani N, Kurth T, Hunziker EB (2007) Expression of cartilage-related genes in bovine synovial tissue. J Orthop Res 25: 813-819.

Smolders LA, Bergknut N, Grinwis GC, Hagman R, Lagerstedt AS, Hazewinkel HA, Tryfonidou MA, Meij BP (2013) Intervertebral disc degeneration in the dog. Part 2: Chondrodystrophic and non-chondrodystrophic breeds. Vet J 195: 292-299.

Sobajima S, Vadala G, Shimer A, Kim JS, Gilbertson LG, Kang JD (2008) Feasibility of a stem cell therapy for intervertebral disc degeneration. Spine J 8: 888-896.

Solorio LD, Fu AS, Hernandez-Irizarry R, Alsberg E (2010) Chondrogenic differentiation of human mesenchymal stem cell aggregates via controlled release of TGFbeta1 from incorporated polymer microspheres. J Biomed Mater Res Part A 92: 1139-1144.

Spillekom S, Smolders LA, Grinwis GC, Arkesteijn IT, Ito K, Meij BP, Tryfonidou MA (2014) Increased osmolarity and cell clustering preserve canine notochordal cell phenotype in culture. Tissue Eng Part C Methods [Epub ahead of print. PMID: 24304309].

Stoyanov JV, Gantenbein-Ritter B, Bertolo A, Aebli N, Baur M, Alini M, Grad S (2011) Role of hypoxia and growth and differentiation factor-5 on differentiation of human mesenchymal stem cells towards intervertebral nucleus pulposus-like cells. Eur Cell Mater 21: 533-547.

Strassburg S, Richardson SM, Freemont AJ, Hoyland JA (2010) Co-culture induces mesenchymal stem cell differentiation and modulation of the degenerate human nucleus pulposus cell phenotype. Regen Med 5: 701-711.

Vadala G, Sowa G, Hubert M, Gilbertson LG, Denaro V, Kang JD (2012) Mesenchymal stem cells injection in degenerated intervertebral disc: cell leakage may induce osteophyte formation. J Tissue Eng Regen Med 6: 348-355.

Watanabe T, Sakai D, Yamamoto Y, Iwashina T, Serigano K, Tamura F, Mochida J (2010) Human nucleus pulposus cells significantly enhanced biological properties in a coculture system with direct cell-to-cell contact with autologous mesenchymal stem cells. J Orthop Res 28: 623-630.

Wuertz K, Godburn K, Neidlinger-Wilke C, Urban J, Iatridis JC (2008) Behavior of mesenchymal stem cells in the chemical microenvironment of the intervertebral disc. Spine 33: 1843-1849.

Yoshikawa T, Ueda Y, Miyazaki K, Koizumi M, Takakura Y (2010) Disc regeneration therapy using marrow mesenchymal cell transplantation: a report of two case studies. Spine 35: E475-E480.

Zeiter S, Lezuo P, Ito K (2009) Effect of TGF beta1, BMP-2 and hydraulic pressure on chondrogenic differentiation of bovine bone marrow mesenchymal stromal cells. Biorheology 46: 45-55.

Zhang YG, Guo TM, Guo X, Wu SX (2009) Clinical diagnosis for discogenic low back pain. Int J Biol Sci 5: 647-658.

Zhao CQ, Wang LM, Jiang LS, Dai LY (2007) The cell biology of intervertebral disc aging and degeneration. Ageing Res Rev 6:247-261.

\section{Discussion with Reviewers}

Reviewer I: How can notochordal cells be best utilised in terms of identifying their therapeutic potential?

Authors: As NCs can only be obtained from deceased young or foetal human donors, their direct use is limited even for in vitro experiments. It is then crucial to identify the factors involved in their positive effects on NPCs and BMSCs. As this influence seems to be intrinsic to their native state and culture conditions maintaining their original phenotype are still difficult to define, it appears essential to work with freshly isolated NCs or NP fragments to be able to identify the soluble factors mediating the NC's effects. The therapeutical strategy will then be to use these factors or their active components and not the NCs anymore, to be free of the problem of cell supply.

Reviewer II: For further application of the disc cellspecific bioactive factors in notocordal cell conditioned medium, how would you identify these factors?

Authors: The fact that NCs lose their phenotype and their effects on NPCs and BMSCs when cultured can, in fact, be used as an advantage. Cultured NCs do not have an effect anymore while fresh NCs do. Thus, it would appear that cultured NCs are not secreting the influential 
factor(s) anymore. We are currently analysing the differential secretory profiles of fresh NCs $v s$. cultured NCs using broad proteomics techniques to identify potential candidates mediating the positive effect of NCCM.

Reviewer III: The authors do not present relative gene expression data on the side of the $\mathrm{NC}$ before and after co-culture. What do the authors think about the nature of these relatively large and vacuole-containing cells? Do they change their phenotype in culture and if so into which cell type do they transform?

Authors: As the NPCs and NCs were mixed in the alginate beads it was not possible to analyse the cells separately. Unfortunately, the authors were not able to design porcine-specific primers allowing measurement of $\mathrm{NC}$ gene expression alone. Based on previous experiments in same culture conditions, but where porcine NCs and bovine NPCs were separated by a permeable membrane (Ito et al., 2013), NCs decrease their gene expression of cytokeratin-8/-18 and Brachyury already after $4 \mathrm{~d}$ of culture. Broader phenotypical analysis is required in order to determine into which cell type the NCs differentiate in culture. As the disc only contains NCs and NPCs throughout life, however, the authors do not expect the NCs to differentiate into another cell type. As the change of NC phenotype is also associated with a decrease in aggrecan gene expression, it seems that NCs are dedifferentiating toward a fibroblast-like cell phenotype rather than differentiating in culture, as can been with chondrocytes for example.

As for the nature of the NCs, it is still debated. From the authors' point of view, the accumulating work conducted on these cells makes it clear that they are involved in disc homeostasis. Their positive influence, however, is intrinsic to their original phenotype (large vacuolated cell). When they transform in vivo, most likely into NPCs or a similar cell type, they lose their ability to help NP maintenance. 